\title{
Comparative Study of Different Energy Management Strategies for Dual-Source Electric Vehicles
}

\author{
João P. Trovão ${ }^{1,3,4}$, Victor D. N. Santos ${ }^{1,3}$, Paulo G. Pereirinha ${ }^{1,3,4}$, Humberto M. Jorge ${ }^{2,3}$, \\ Carlos Henggeler Antunes ${ }^{2,3}$ \\ ${ }^{1}$ DEE-ISEC, Polytechnic Institute of Coimbra, P-3030-199, Coimbra, Portugal, \{jtrovao,vsantos, ppereiri\}@isec.pt \\ ${ }^{2}$ DEEC - FCTUC, University of Coimbra - Pólo II, P-3030-290 Coimbra, Portugal, \{hjorge, ch\}@deec.uc.pt \\ ${ }^{3}$ INESC-Coimbra, Institute for Systems and Computers Engineering at Coimbra, P-3000-033 Coimbra, Portugal \\ ${ }^{4}$ APVE, Portuguese Electric Vehicle Association, Portuguese Branch of AVERE, P-1049-001 Lisboa, Portugal
}

\begin{abstract}
This paper presents a comparative analysis between a pure battery electric vehicle and a dual-source electric vehicle endowed with a multi-level energy management strategy. The energy management of multi-source electric vehicles is a crucial aspect to obtain an effective contribution of the power sources, namely one with high specific energy and another with high specific power. This issue is particularly relevant for electric vehicles subject to high accelerations, breaking and those performing a large number of start and stop in its driving cycle. A comprehensive energy management system architecture with different management levels is presented and compared with a rule-based strategy (power disaggregation) and a pure battery electric vehicle. Simulations have been performed for two different urban driving cycles (NYCC and ARTEMIS low power urban) in order to validate and compare the effectiveness of the strategies under study. The results obtained show the usefulness of the proposed multi-level energy management strategy based on an integrated rule-based meta-heuristic approach versus an energy management strategy directed by the power disaggregation concept. The proposed approach increases the electric vehicle performance due to a better usage of the sources, which leads to a reduced installed power capacity.
\end{abstract}

Keywords: Energy Storage, Power Management, Efficiency, Battery, EDLC (Electric Double-Layer Capacitor)

\section{Introduction}

New vehicular applications, namely Electric Vehicles (EV) and Hybrid Electric Vehicles (HEV) have been developed in recent years thus contributing to reach the (local) zero emissions target and achieve more sustainable transportation solutions. In order to increase the performance and autonomy of EV an extensive work has been performed on the selection of power sources and the proposal of innovative energy management strategies that promote energy efficiency by capturing the regenerative energy retrieved from breaking and downhill.

The most common and mature power sources candidates suitable for EVs are batteries (bat), Super-Capacitors (SC) and Fuel-Cells (FC). Despite power sources can be used separately, the use of multiple power sources in EV has gained acceptance, both among researchers and the automotive industry [1]. The hybridization of power sources in EV has clear advantages when compared with a single power source scenario. 
High Specific Energy (HSE) sources, as batteries and $\mathrm{FC}$, are adequate to feed constant power loads, but they are not so efficient feeding loads with high power demand variations. For this kind of loads, a High Specific Power (HSP) source is needed, and currently SCs are major candidates for providing HSP $[2,3]$.

The association of energy sources, under the hybridization concept, is performed by DC-DC converters, namely two quadrant DC-DC converters for batteries and SC. DC-DC converters are devices that convert a low voltage into a higher voltage level or conversely accordingly to the EV operation mode.

In active parallel topology, one DC-DC converter per power source is used. The input voltage of each DC-DC converter can therefore assume different values, being its output adjusted based on the shared DC link voltage value [4]. This topology is presented in Figure 1.

This configuration requires an accurate Energy Management Strategy (EMS) managing the amount of power that each source should give to and/or receive from the DC link for all EV operation modes [5]. EMS in a multi-source system should consider the power sources response under different power demands profiles [6] aiming to increase the batteries State of Charge (SoC), keeping the SCs at the optimum $\mathrm{SoC}$, as well as maximising the available energy of both systems $[6,7]$.

Nowadays, commercially available EVs are based exclusively on batteries, leading to difficulties in terms of their cost, volume and weight [1].

The energy management problem in hybridized sources EV is generally simplified using the prior knowledge of the vehicle route and consequently the requested power values (e.g. bus/tramway journeys). For this type of application, some authors presented a power management strategy based on the disaggregation of the power demand signal, using its frequency information, and the DC link voltage regulation for known driving cycles [8]. However, this approach presents limitations and requires an accurate sizing of the energy sources on the vehicle to be effective, generally leading to an oversize of the source with HSP. Another key aspect is the maintenance of the journey conditions and the resultant power profile demand. Daily variations in the number of passengers and the traffic conditions caused by traffic jams and start and stop events preclude the use of this type of strategy in real on-road mobility [6].

Due to these drawbacks, EMS are required for actual applications offering good solutions for practical purposes and effective distribution of embarked energy [7]. Some approaches tend to focus more on the feasibility of methods in embedded systems enabling power-sharing decisions in real-time for multiple energy storage systems to enable the optimum power flow [7-9]. For instance, in [7] the management strategies are based on an improved management architecture in which a dynamically restricted search space strategy coupled with a simulated annealing technique is exploited to accomplish the global optimization of the EMS.

The study presented in this paper aims at evaluating the performance of two topologies (batteries only and batteries plus SC) and two EMS for a hybridized dual-source EV based on batteries and SCs.

An overview of the driving cycles and energy sources topology is presented in Section 2. The EMS description is made in Section 3. Simulation and comparison of the different strategies and results for normalized driving cycles for a real EV are presented in section 4 . The main conclusions are drawn in section 5 .

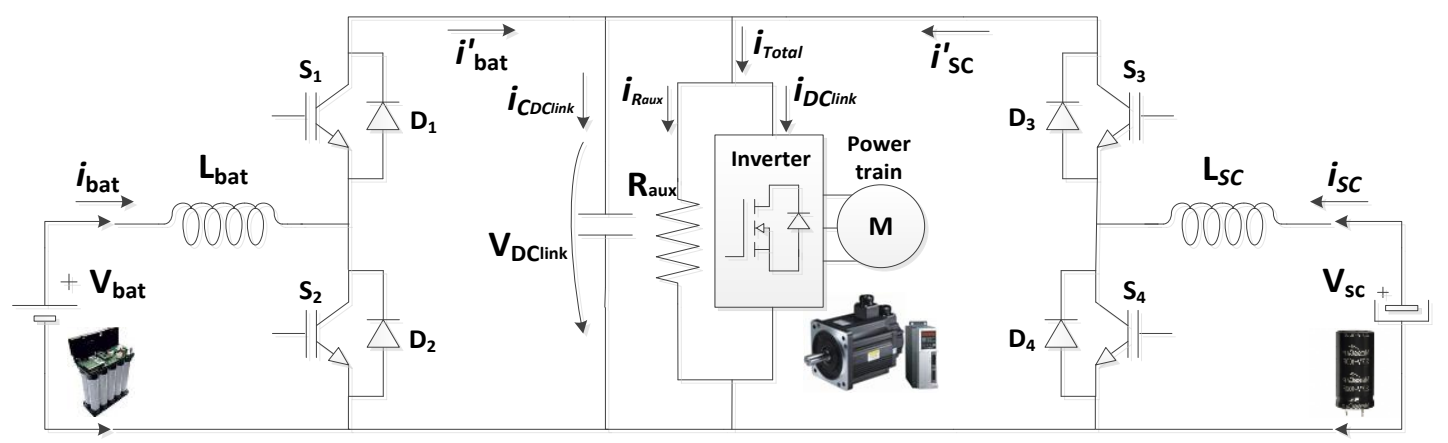

Figure 1: A dual-source (batteries and SCs) topology. 


\section{Driving Cycles and Energy Sources Topology}

To perform a comparative study among the implemented EMS, under the proposed power hybridization scenario, two standard urban driving cycles are used: EPA New York City Cycle (NYCC) and ARTEMIS Low Motor Urban Total (ARTEMIS) [12]. These driving cycles are speed-time sequences that represent the traffic conditions and driving behaviour in urban areas. For a better comparison (distance and time) among scenarios two NYCC cycles have been concatenated resulting in the sequence of similar duration displayed in Figure 2. The driving cycles main parameters are presented in Table I.

In addition, for this study the EV is based on the GL 162 Ligier small urban vehicle (VEIL project) as presented in Figure $3[10,11]$.

Based on the information of the NYCC and ARTEMIS (upper graphs of Figure 2) vehicle speed profile $v_{\text {cycle }}(t), t \in[0, T]$, vehicle characteristics, the mechanical power, $P_{\text {mec }}$ cycle $(t), t \in[0, T]$, at the vehicle wheel is computed. The efficiency values are applied to the $P_{\text {mec }}$ cycle $(t)$ in order to compute the electrical power demand, $P_{d e m}(t), t \in[0, T]$, requested from the sources [11]. The values are evaluated in order to analyse the different feeding system topologies and are depicted in the lower graphs of Figure 2.

The hybrid topology illustrated in Figure 1, comprises two types of energy sources: i) a battery pack composed of two banks in parallel of eight NiMH Saft modules (12 V and $13 \mathrm{Ah}$ ) in series, and ii) a SC bank composed of two branches of SC banks in parallel of a series of five modules $(330 \mathrm{~F}, 16.2 \mathrm{~V}$, and $605 \mathrm{~A})$ manufactured by Maxwell. The sources characteristics are specified in Table 2.
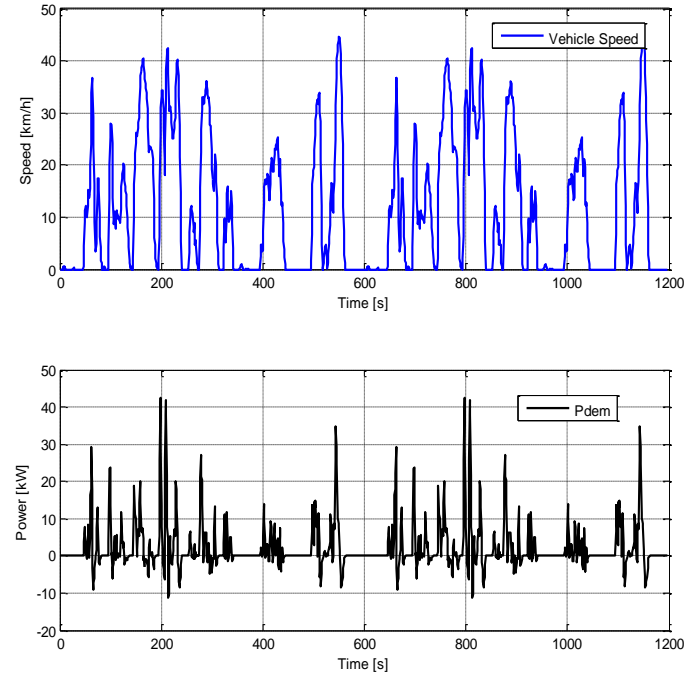

a) Two concatenated NYCC
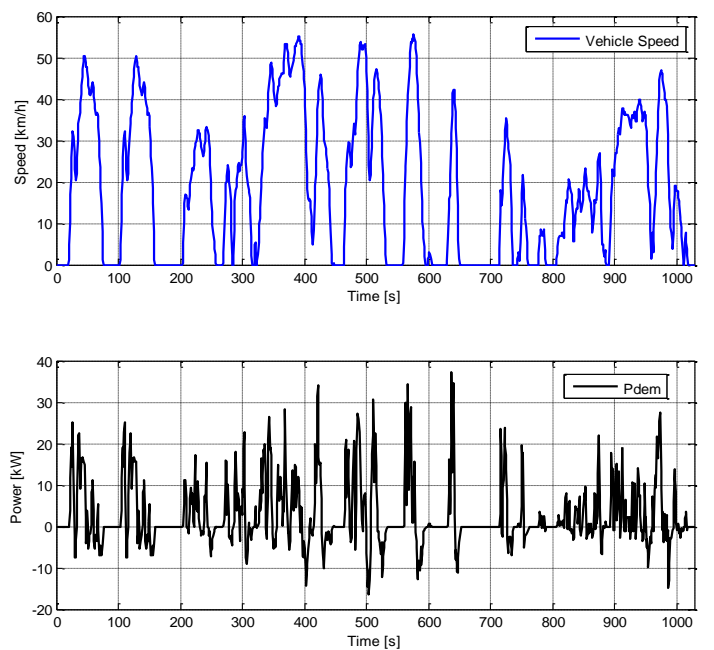

a) ARTEMIS Low Urban

Figure 2: Speed and VEIL electrical power demand for the driving cycles.

Although more precise mathematical models for batteries and SCs are available in the literature [7], a simplified model depicted in Figure 4 is used to analyse the efficiency of the different EMS. This model allows the performance analysis of the strategies under study [5, 7].

Table 1: Main parameters of the driving cycles

\begin{tabular}{|c|c|c|c|c|c|c|c|c|c|c|}
\hline \multirow[b]{2}{*}{$\begin{array}{l}\text { Driving } \\
\text { Cycle }\end{array}$} & \multirow{2}{*}{$\begin{array}{c}\text { Standing } \\
{[\%]}\end{array}$} & \multirow[b]{2}{*}{$\begin{array}{l}\text { Driving } \\
{[\%]}\end{array}$} & \multicolumn{4}{|c|}{ Driving } & \multirow{2}{*}{$\begin{array}{l}\text { Average } \\
\text { speed } \\
{[\mathrm{km} / \mathrm{h}]}\end{array}$} & \multirow{2}{*}{$\begin{array}{c}\text { Maximum } \\
\text { speed } \\
{[\mathrm{km} / \mathrm{h}]}\end{array}$} & \multirow{2}{*}{\begin{tabular}{|c|} 
Total \\
distance \\
{$[\mathrm{km}]$}
\end{tabular}} & \multirow{2}{*}{$\begin{array}{l}\text { Time } \\
{[\mathrm{min}]}\end{array}$} \\
\hline & & & $\begin{array}{c}\text { Cruising } \\
{[\%]}\end{array}$ & $\begin{array}{c}\text { Accelerating } \\
{[\%]}\end{array}$ & $\begin{array}{c}\text { Decelerating } \\
{[\%]}\end{array}$ & $\begin{array}{c}\text { Breaking } \\
{[\%]}\end{array}$ & & & & \\
\hline $\begin{array}{c}\text { NYCC } \\
{[0,598]}\end{array}$ & 31.10 & 68.90 & 10.20 & 29.43 & 29.26 & 21.57 & 11.5 & 44.45 & $3.806^{\S}$ & $19.93^{\S}$ \\
\hline $\begin{array}{l}\text { ARTEMIS } \\
{[0,1028]}\end{array}$ & 23.54 & 76.46 & 8.85 & 33.66 & 33.95 & 24.42 & 18.6 & 54.87 & 5.319 & 17.13 \\
\hline
\end{tabular}

${ }^{8}$ for two concatenated NYCC. 


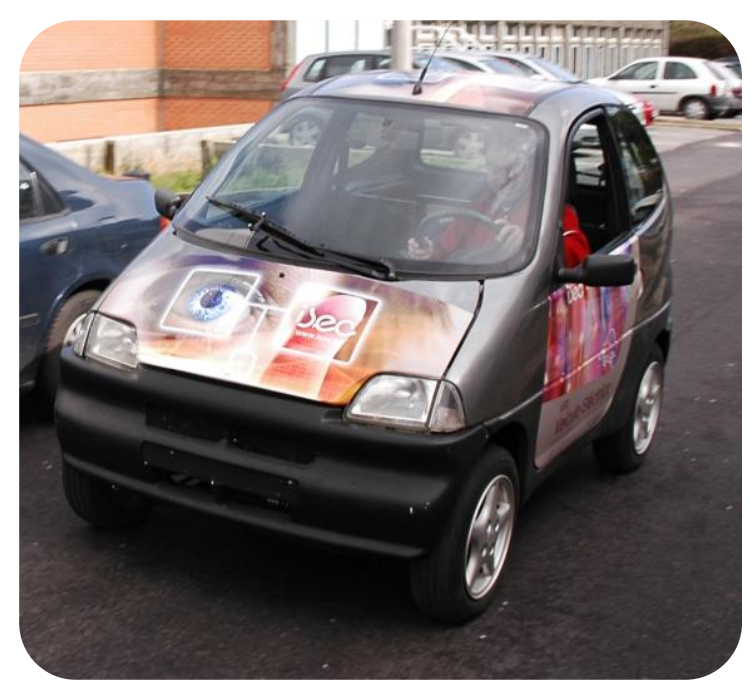

Figure 3: VEIL project on road tests at ISEC campus.

Table 2: Energy Sources' Characteristics

\begin{tabular}{lccc}
\hline \multicolumn{1}{c}{ Variable } & Symbol & Value & Units \\
\hline Battery (12V SAFT VH modules) & & & \\
\hline Battery bank Power & $P_{\text {bat }}$ & {$[-1.2,5.8]$} & $\mathrm{kW}$ \\
Battery bank State of Charge Limits & $S o C_{\text {bat }}$ & {$[0.2,1]$} & - \\
Min. Battery bank open-circuit voltage & $V_{\text {bat }}^{\text {OC min }}$ & 97.47 & $\mathrm{~V}$ \\
Battery bank no-load voltage drop & $\delta_{\text {bat }}$ & 17.03 & $\mathrm{~V}$ \\
Number of batteries in series & $N_{\text {bat }}$ & 8 & - \\
Number of battery's bank in parallel & $n_{\text {bat }}$ & 2 & - \\
\hline Supercapacitors (MAXWELL & BMODO330 & modules) \\
\hline SC bank Capacitance & Cap & 132 & $\mathrm{~F}$ \\
SC bank Power & $P_{S C}$ & {$[-90,90]$} & $\mathrm{kW}$ \\
SC bank State of Charge Limits & $S o C_{S C}$ & {$[0.4,1]$} & - \\
Min. SC bank open-circuit voltage & $V_{S C}^{\text {OC min }}$ & 0 & $\mathrm{~V}$ \\
SC bank no-load voltage drop & $\delta_{S C}$ & 81 & $\mathrm{~V}$ \\
Number of SC's module in series & $N_{S C}$ & 5 & - \\
Number of SC's bank in parallel & $n_{S C}$ & 2 & - \\
\hline
\end{tabular}

The model evaluates the no-load voltage, using the updating of the SoC and the discharge or charge current. This evaluation is performed recursively using equations (1), (2) and (3) for the source $j \in\{b a t, S C\}$.

$$
\begin{gathered}
Q_{j}[k+1]=Q_{j}[k]-I_{j}[k] \cdot \frac{\Delta t}{3600} \\
\operatorname{SoC}_{j}(t)=\frac{Q_{j}(t)}{Q_{j_{R e f}}}
\end{gathered}
$$

$$
v_{j}^{O C}[k]=V_{j}^{O C \_ \text {min }}+\delta_{j} \cdot S o C_{j}[k]
$$

where $Q_{j}$ is the source capacity $(\mathrm{Ah}) ; I_{j}$ is the source current (A); and $\Delta \mathrm{t}$ is the integration time step [s].

The global model including the EMS is implemented in Matlab ${ }^{\circledR}$ environment.

\section{Energy Management Strategies}

To perform the comparative study of the implemented EMS, two EV configurations and two EMS strategies have been simulated for the driving cycles. The EV configurations are an EV with battery only (BEV) and an EV with multisources (MSEV). For the last configuration, a parallel active topology is considered and the EMS strategies are based on a frequency disaggregation method (MSEV-EMS(1)) and the optimized multilevel energy management (MSEV-EMS(2)).

\subsection{Multi-Level Energy Management}

The power management problem consists in determining, in real time, the power share between the two sources while keeping the SCs at the optimum $\mathrm{SoC}$ as well as maximising the available energy of both systems. These two problems cannot be completely decoupled and should be jointly addressed. The optimized approach is established with a long-term and short-term management models fully explained in [6].

Therefore, this planning strategy should define a method to keep the SoC of the SCs at an appropriate level for any request.

The fundamental equation in the proposed problem is (4).

$$
P_{\text {dem }}(t)=\sum_{j \in\{b a t, S C\}} P_{j}(t), \forall t
$$

where $P_{\text {dem }}(t)$ is the power demand of the system and $P_{j}(t)$ is the power to be supplied by each of the sources, with $j \in\{b a t, S C\}$.

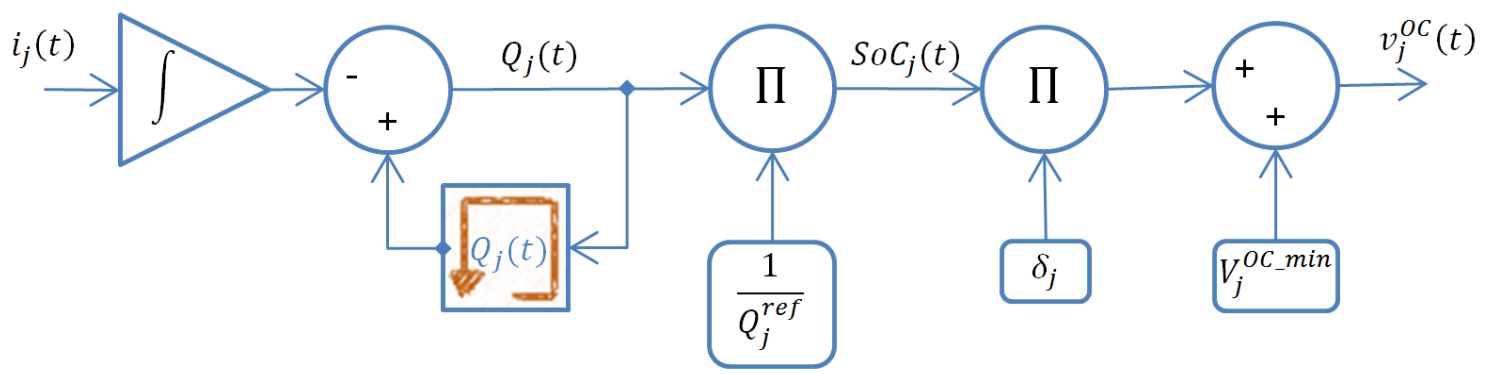

Figure 4: Generic model for energy source. 
Considering $\left|P_{j}^{\min }\right|=\left|P_{j}^{\max }\right|, \quad P_{j}(t)$ can be expressed in terms of $C_{j}(t)$ :

$$
\begin{gathered}
P_{j}(t)=C_{j}(t) \cdot P_{j}^{\max }, \\
\text { for } C_{j}(t) \in\left[L B_{j}, U B_{j}\right], \forall t
\end{gathered}
$$

$C_{j}(t)$ are limited by a lower bound $L B_{j}$ that sets the charge capacity of source $j$ and upper bound $U B_{j}$ that defines the discharge ability of source $j$. Typically, $L B_{j} \in[-1,0]$ and $U B_{j} \in[0,1]$. However, for battery technology, $L B_{\text {bat }}^{\max }$ is $20 \%$ of $U B_{\text {bat }}^{\max }$, due to the lower capacity of the charging mode for most batteries.

The high level management strategy is defined based on a set of rules, mainly established by experience and expert knowledge, using the values of the SoC for battery and $\mathrm{SC}, S_{0} C_{j}(t)$, and the power demand of the supply system, $P_{\text {dem }}(t)$, at every instant $t$. The power management, for short-term planning, has to define a real-time energy share under the strict guidelines of strategy planning based on the long-term rules mentioned above and the evaluation function in (6). This short-term planning creates a set of decision problems, the solution of which generates a high quality endusage of the energy at the end of the journey. To supply the power requested by the EV without interruption and degradation of the EV sources, the power management module decisions should be made within the effective space constraints defined by the energy management level according to the driver requests.

This module has been implemented using a metaheuristic approach to optimize the energy share between sources in real-time. Thus, as established in the second level management, the minimization of the difference between the power demand, $P_{d e m}$, and the power supplies, $P_{j}$, at each time interval $k$ corresponds to solve (6).

$$
\begin{aligned}
f_{o}=\min _{C_{b a t}, C_{S C}} \mid P_{\text {dem }}[k] & \\
& -\left[C_{b a t}[k] \cdot P_{\text {bat }}^{\max }[k]\right. \\
& \left.+C_{S C}[k] \cdot P_{S C}^{\max }[k]\right] \mid \\
& \forall k \in\{1, \ldots, N\}
\end{aligned}
$$

Subject to:

$$
\begin{aligned}
& L B_{j}[k] \leq C_{j}[k] \leq U B_{j}[k] ; \\
& P_{j}[k]=C_{j}[k] \cdot P_{j}^{\max }[k] ; \\
& (1),(2), \text { and }(3) ; \\
& P_{j}^{\max }[k+1]=v_{j}^{o C}[k] \cdot I_{j_{-R e f}} ; \\
& P_{j}^{\min }[k] \leq P_{j}[k] \leq P_{j}^{\max }[k] ; \\
& \text { with } \in\{\text { bat }, S C\}, k \in\{1, \ldots, N\} .
\end{aligned}
$$

\subsection{Management based on the Power Signal Frequency Disaggregation}

To implement the MSEV-EMS(1), a frequency disaggregation method has been used to distribute the power requested to the EV sources. The electrical power demand is separated in two components: the low-frequency power variations use mainly the batteries, being the high-frequency power variations supported by the SC. This separation is achieved using a high pass filter (7) as illustrated in Figure 5.

$$
P_{S C}=P_{d e m} \cdot \frac{\tau_{H F} \cdot s}{\tau_{H F} \cdot s+1}
$$

The power requested to the SC aims to cope with the high variability contents of the power demand, while the average power is provided by the batteries. Even if this EMS is not the main topic of this work it presents a practical way to compare our EMS architecture with a strategy that needs a prior knowledge of the $\mathrm{EV}$ power demand.

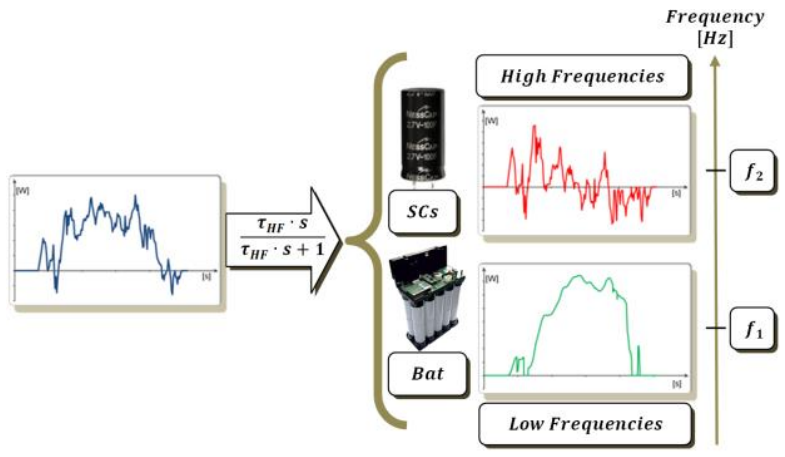

Figure 5: Power signal frequency disaggregation.

\section{Results for the Normalized Driving Cycles}

The simulation results for BEV, MSEV-EMS(1) and MSEV-EMS(2) for 2xNYCC and ARTEMIS cycles are presented in Figure 6 . The results of MSEV-EMS(2) are only for one of the twenty runs, considering that for the complete set of the Simulated Annealing (SA) algorithm computations the standard deviation of the final value of $S o C_{b a t}$ is always below $0.08 \%$.

The results show that to feed this EV, for the driving cycles under study, the BEV topology requires oversized batteries (above $42 \mathrm{~kW}$ ). This battery power value is greater than the one required by a dual-source system with optimized EMS. 


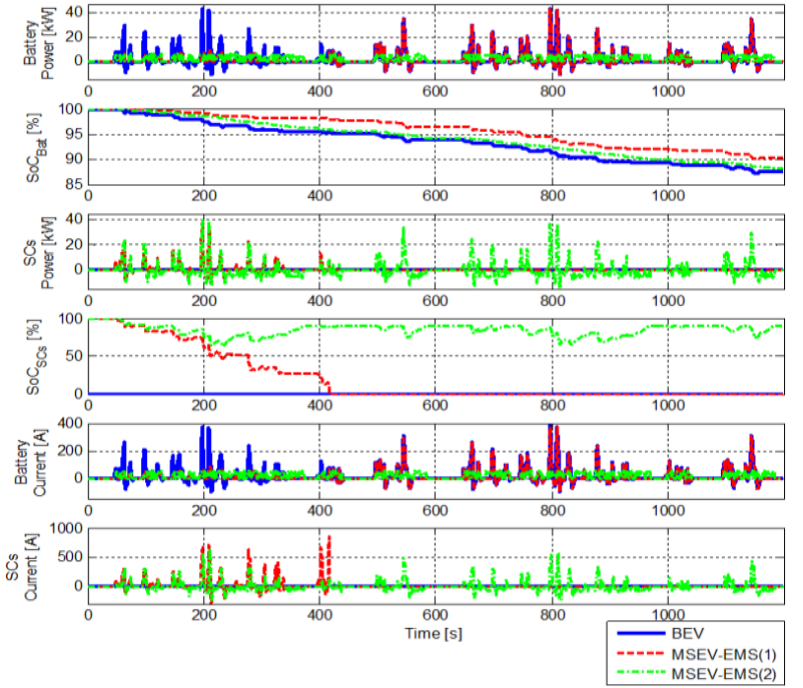

a)

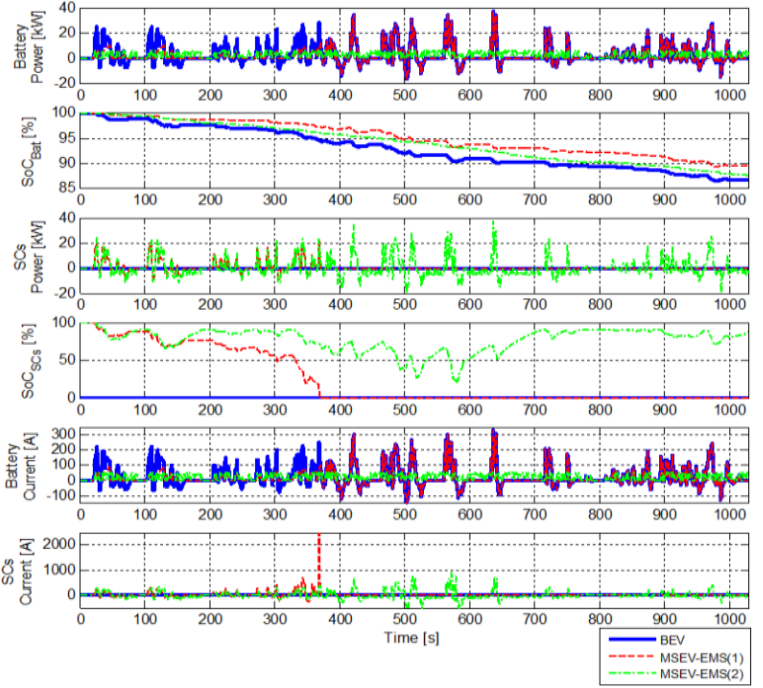

b)

Figure 6: Driving Cycle Results for BEV (full blue line), MSEV-EMS(1) (dashed red line) and MSEV-EMS(2) (dashdotted green line) for: a) 2XNYCC and b) ARTEMIS Low Power Urban.

In fact, the considered batteries provide a maximum current of $25 \mathrm{~A}$ in a continuous time base and a maximum peak current of $80 \mathrm{~A}$ $(0.1 \mathrm{~s}), 50 \mathrm{~A}(0.5 \mathrm{~s})$ and $30 \mathrm{~A}(5 \mathrm{~s})$.

Therefore, these batteries have higher specific energy $(\mathrm{Wh} / \mathrm{kg})$ than specific power $(\mathrm{W} / \mathrm{kg})$. Considering the power required $\left(P_{\text {dem }}\right)$ during the severest acceleration of the driving cycles (NYCC and ARTEMIS) shown in Figure 2, a maximum power above $42 \mathrm{~kW}$ for about $2 \mathrm{~s}$ is required.

Maintaining the voltage level of the battery $(96 \mathrm{~V})$ would require $437.5 \mathrm{~A}$ (which is impractical for these batteries) and lead to use 15 banks of these batteries in parallel. This would increase by $750 \%$ the weight of the batteries installed in the EV and consequently their cost. To increase the specific power of the supply system, the SCs offer HSP that complements the NiMH batteries. Indeed, the SCs used supply a maximum power of $90 \mathrm{~kW}$, with a weight increase of $50 \%$.

For the MSEV-EMS(1), the SCs help the batteries to cover the power peaks while they have energy, but as there is no concern for the SCs optimal energy level these only perform their role until close to $400 \mathrm{~s}$. For the proposed architecture, MSEV-EMS(2), the nominal power of the batteries $(5.8 \mathrm{~kW})$ was never exceeded during the EV operation for these driving cycles. The results show that the EMS attempts to maximize the use of SCs and transfers energy from the batteries to the SCs during the standstill phase when no power is required from the sources. This strategy allows an optimized level of energy in the $\mathrm{SC}$ at each instant.

A quantitative assessment of the proposed realtime EMS architecture for MSEV, MSEVEMS(2), and two other management strategies, namely: i) BEV configuration (pure battery) and ii) Frequency space disaggregation, MSEV-EMS(1) is presented in Figure 7, for these urban driving cycles. These results show that, when the MSEVEMS(2) is used, the SoC of the batteries is maximized and by transferring the remaining stored energy in the SCs at the end of the cycles, the final values of the $S o C_{b a t}$ is $95 \%$ and $94 \%$ (see Figure 7 a)) for NYCC and ARTEMIS, respectively. The battery peak power is only possible for the proposed EMS based on a doublelevel management strategy (Figure $7 \mathrm{~b}$ )).

Thus, to use a pure battery configuration, a huge increase of the battery capacity and weight should be considered. This increase would result in an augmented power demand of the batteries to comply with the increased size. Also for the MSEV-EMS(1) approach an increased capacity of the SCs is needed, with the same conclusion as the previous one, thus leading to a sizing problem. In addition, the energy losses due to high currents in sources are considerably reduced with the MSEVEMS(2), particularly for the SCs under the ARTEMIS driving cycle (Figure $7 \mathrm{c}$ )). Therefore, these results demonstrate that the double-level management strategy, MSEV-EMS(2), is very effective for an optimized management of a dualsource EV and presents advantages in EV efficiency, autonomy and power sources sizing. 
Considering the proposed solutions in terms of energy sources investment, the BEV solution needs 15 banks of NiMH batteries with a total cost of $16500 €$ (2008 prices) [14] and the MSEV solution for MSEV-EMS(1) a requires 2 banks of $\mathrm{NiMH}$ batteries and a 3 times oversizing of the selected SCs, leading to a total cost of $20650 €$. Finally, the MSEV configuration with MSEVEMS(2) presents a very good usage of the combination of 2 banks of NiMH batteries and 2 banks of the selected SCs with a total cost of $8350 €$.

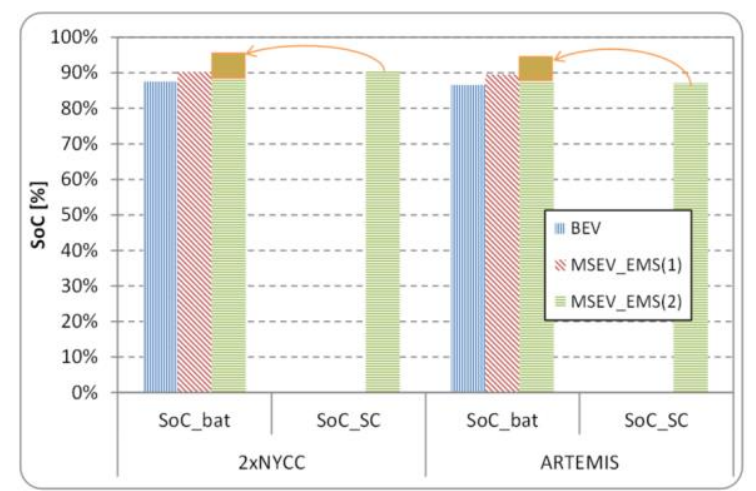

a)

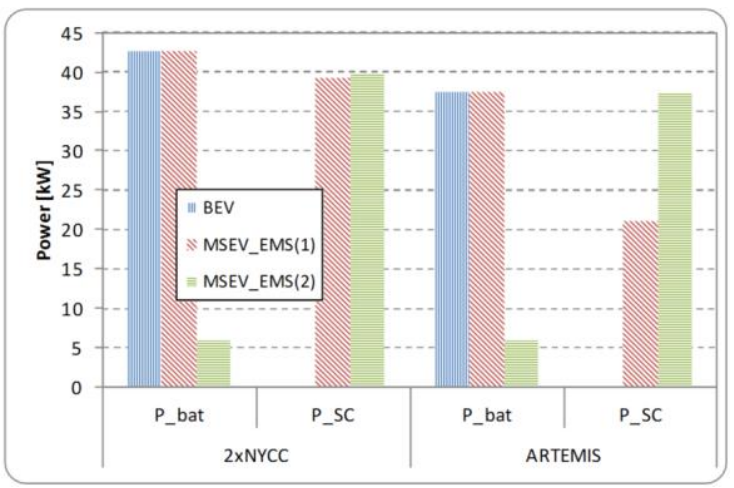

b)

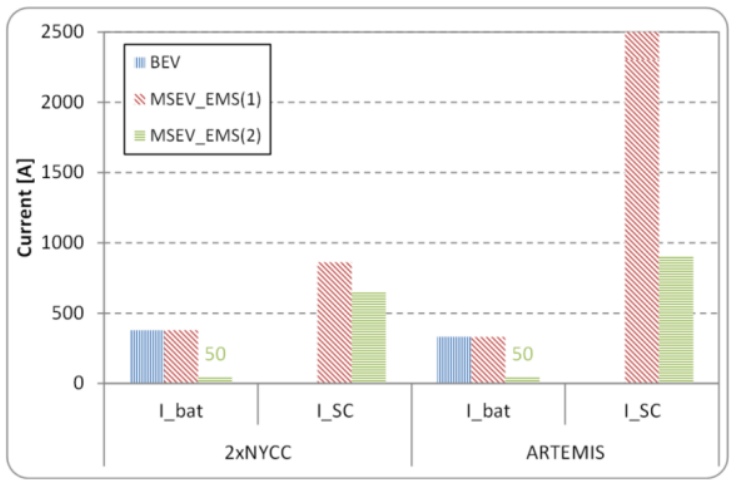

c)

Figure 7. (a) $\mathrm{SoC}$ value at the end of the driving cycle; Maximum power (b) and Maximum current (c) requested to the energy sources during the driving cycle operation.

\section{Conclusions}

In this paper, a typical EMS implementation based on the power demand frequency disaggregation is compared with an EMS based on a multi-level energy management that uses an integrated rulebased meta-heuristic optimization approach.

In this approach, the power demand is split between batteries and SCs to manage the SCs SoC, while the batteries operate mostly at its higher efficiency range.

The comparison focuses on the global efficiency of the power source energy management. The simulations on a dual-source EV (batteries + SCs) have shown the differences between distinct EMS proposals, leading to the conclusion that the double-level management strategy, MSEVEMS(2), effectively manages a dual-source EV displaying advantages in EV efficiency, autonomy and power sources sizing. This approach may lay the foundations for further research the effectiveness of this EMS for future implementations in real-time and different applications.

\section{Acknowledgments}

This work has been framed under the Energy for Sustainability Initiative of the University of Coimbra and supported by the R\&D Project EMSURE Energy and Mobility for Sustainable Regions (CENTRO-07-0224-FEDER-002004) and by FCT through the doctoral grant SFRH/BD/36094/2007 and project grants PTDC/EEA-EEL/121284/2010, FCOMP-01-0124-FEDER-020391, MIT/SET/0018/ 2009, and PEst-C/EEI/UI0308/2011.

\section{References}

[1] C. C. Chan, Y. S. Wong, A. Bouscayrol and K. Chen, Powering Sustainable Mobility: Roadmaps of Electric, Hybrid and Fuel Cell Vehicles, Procs. of the IEEE, vol. 97, n. 4, pp. 603-607, 2009.

[2] M. A. Silva, J.P. Trovão, P. G. Pereirinha, Implementation of a multiple input $D C-D C$ converter for Electric Vehicle power system, Energetics (IYCE), Proceedings of the 2011 3rd International Youth Conference on, pp.18, 7-9 July 2011.

[3] João P. Trovão, Paulo G. Pereirinha, Humberto M. Jorge: Design Methodology of Energy Storage Systems for a Small Electric Vehicle, World Electric Vehicle Journal, vol. 3, pp. 1-12, 2009. 
[4] de Castro, R.; Araújo, R.E.; Trovão, J.P.F.; Pereirinha, P.G.; Melo, P.; Freitas, D.; Robust DC-Link Control in EVs With Multiple Energy Storage Systems, IEEE Transactions on Vehicular Technology, vol.61, no.8, pp.3553-3565, 2012.

[5] A.-L. Allègre, R. Trigui and A. Bouscayrol, Different Energy Management Strategies Of Hybrid Energy Storage System (HESS) Using Batteries And Supercapacitors For Vehicular Applications, IEEE Vehicle Power and Propulsion Conference (VPPC), pp. 1-6, Sep. 2010.

[6] João P. Trovão, Paulo G. Pereirinha, Humberto M. Jorge, Carlos Henggeler Antunes, A multi-level energy management system for multi-source electric vehicles An integrated rule-based meta-heuristic approach, Applied Energy, Volume 105, pp. 304-318, 2013.

[7] J. P. F. Trovao, V. D. N. Santos, P. G. Pereirinha, H. M. Jorge, and C. H. Antunes: A Simulated Annealing Approach for Optimal Power Source Management in a Small EV, IEEE Transactions on Sustainable Energy, vol. 4, no. 4, pp.1-10, 2013.

[8] P. Thounthong, S. Raël, B. Davat, Energy Management of Fuel Cell/Battery/ Supercapacitor Hybrid Power Source for Vehicle Applications, Journal of Power Sources, vol. 193, no. 1, pp. 376-385, 2009.

[9] Yi-Hsuan, H.; Chien-Hsun, W.: An integrated optimization approach for a hybrid energy system in electric vehicles, Applied Energy, vol. 98, pp. 479-490, 2012.

[10] Romaus, C.; Gathmann, K.; Böcker, J.: Optimal energy management for a hybrid energy storage system for EVs based on stochastic dynamic programming, 6th IEEE Vehicle Power and Propulsion Conference, VPPC 2010, Lille, France, September 1-3, 2010.

[11] P. G. Pereirinha, J. P. Trovão, L. Marques,, J. Silvestre, F. Santos, A. Campos, M. Silva, P, Tavares: The Electric Vehicle VEIL Project: A Modular Platform for Research and Education, 2.nd European Ele-Drive Transportation Conference (EET-2007), Conf. Proc., May/Jun. 2007.

[12] Paulo G. Pereirinha, João P. Trovão, L. Marques, M. Silva, J. Silvestre, F. Santos: Advances in the Electric Vehicle ProjectVEIL Used as a Modular Platform for Research and Education, EVS24 International Battery, Hybrid and Fuel Cell Electric Vehicle Symposium, Stavanger, Norway, 13-16 May 2009.
[13] T. J. Barlow, S. Latham, I. S. McCrae, P. G. Boulter, A reference book of vehicle driving cycles for use in the measurements of road vehicles emissions, TRL Limited, Tech. Rep., 2009.

[14] Paulo G. Pereirinha and João P. Trovão (2012). Multiple Energy Sources Hybridization: The Future of Electric Vehicles?, New Generation of Electric Vehicles, Z. Stevic (Ed.), InTech.

\section{Authors}

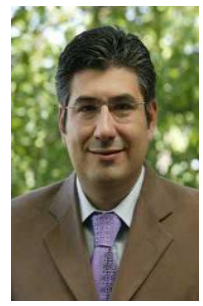

João Pedro F. Trovão received his Ph.D. degree in Electrical Engineering (Power Systems) from the University of Coimbra, Coimbra, Portugal, in 2013. Since 2000, he has been with the Polytechnic Institute of CoimbraCoimbra Institute of Engineering (IPC-ISEC), where he is currently an Assistant Professor with the Department of Electrical Engineering. His research interests cover the areas of electric vehicles, renewable energy, energy management, power quality and rotating electrical machines. He is a member of the Portuguese Electric Vehicle Association (APVE).

Victor D. N. Santos received the Ph.D. degree in electrical engineering from the University of Aveiro, Aveiro, Portugal (2004). Since 2001, he has been with the Polytechnic Institute of Coimbra-Coimbra Institute of Engineering (IPC-ISEC), where he is currently an Assistant Professor with the Department of Electrical Engineering. His research interests include radio resource management, satellite communications, propagation models and localization in indoor environments.

Paulo G. Pereirinha received the Ph.D. degree in electrical engineering from the University of Coimbra, Coimbra, Portugal. Since 1995, he has been with the Polytechnic Institute of CoimbraCoimbra Institute of Engineering (IPC-ISEC), where he is currently a Coordinator Professor with the Department of Electrical Engineering and the President of the Scientific

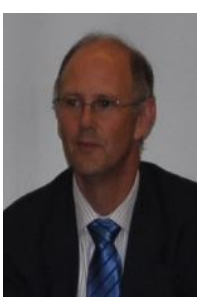
Committee. His classes and research interests include electrical machines, electric vehicles, electromechanical drives, finite elements, and renewable energies. $\mathrm{He}$ is a founder and administration board member of the Portuguese Electric Vehicle Association (APVE). 
Humberto M. Jorge received his Electrical Engineering degree in 1985 and his $\mathrm{PhD}$ degree in 1999, both from the University of Coimbra, Coimbra, Portugal. He is Auxiliary Professor at

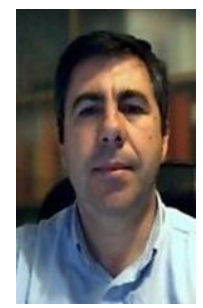
the Department of Electrical and Computer Engineering of University of Coimbra, Coimbra, Portugal. His research interests include power systems, load research, load forecast, load profile, power quality, power distribution, energy efficiency and energy storage.
C. H. Antunes received his Ph.D. degree in Electrical Engineering (Optimization and Systems Theory)

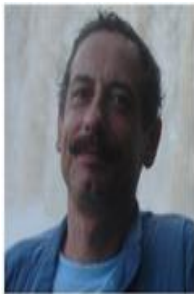
from the University of Coimbra, Coimbra, Portugal, in 1992. He is a full professor at the Department of Electrical and Computer Engineering, University of Coimbra, Coimbra, Portugal. His research areas include multiple objective optimization and energy planning. 